\title{
Optimalisasi Peta Pengendalian Penduduk untuk Diintegrasikan pada Organisasi Perangkat Daerah (OPD) di Kabupaten Bandung Barat
}

\author{
Edsryan Puspadianis Ramitha S Putri, Muhammad Rozahi Istambul \\ Universitas Widyatama, Jl. Cikutra No. 204A, Sukapada, Cibeunying Kidul, Bandung City, 40125, West Java
}

\section{ARTICLE INFORMATION}

Received: February $25^{\text {th }}, 2020$

Revised: April 9 $9^{\text {th }}, 2020$

Available online: April $15^{\text {th }}, 2020$

\section{KEYWORDS}

Demographic Maps, Population Control, Data Integration, Optimization, Duplication

CORRESPONDENCE

Phone: +62 (0818) 427986

E-mail: rozahi.istambul@widyatama.ac.id

\section{INTRODUCTION}

Peta demografi merupakan peta data yang dibutuhkan untuk menunjukan perkembangan penduduk dengan berbagai aspek pendukung seperti usia, jenis kelamin, pendidikan, profesi, alamat dan status kependudukannya. Tetapi data tersebut tidak dapat digunakan begitu saja untuk melakukan pendataan, pencatatan, penghitungan, pelaporan, dan rekapitulasi.

Demografi merupakan ilmu yang mempelajari jumlah persebaran, terotirial, dan kompsisi penduduk serta perubahan-perubahannya dan sebab dari perubahan tersebut [1]. Untuk itu diperlukan peran sistem informasi geografis untuk melakukan pengolahan data pengendalian penduduk yang berdasarkan hasil pendataan keluarga sehingga penyajian informasi demografi dapat sesuai dengan harapan.
Sistem informasi geografis merupakan suatu sistem informasi khusus mengelola data yang memiliki informasi spasial [2].

Penggunaan sistem informasi geografis tak lepas dari peran teknologi informasi yang tentunya banyak permasalahan yang dapat diselesaikan oleh dukungan TI (Teknologi Informasi). Perkembangan teknologi informasi yang berkembang pesat, serta pemanfaatan budaya masyarakat juga terlibat, dan memberikan kontribusi pada penggunaan kemampuan teknologi informasi sebagai upaya mengefisiensikan dan mengefektifkan suatu kegiatan [3]. Dalam pendataan keluarga saat ini masih dilakukan secara manual karena sistemnya masih door to door agar data yang dihasilkan lebih tepat, real, dan sesuai dengan krtiterianya namun ternyata dalam pengelolaan datanya masih tidak efektif yang menyebabkan ada beberapa duplikasi pekerjaan. Pada tahap hasil akhir inilah yang menjadi 
masalah karena pendataan dikelola hanya setiap tahun, kemudian untuk menampilkan hasil pendataannya belum dapat dilihat oleh OPD karena laporan yang dihasilkan hanya di gunakan oleh dinas terkait saja sehingga kurang efektif OPD untuk mengetahui data tersebut.

Saat ini hasil pendataan keluarga di Kabupaten Bandung Barat sangat penting dilakukan tujuannya adalah untuk mengkoordinasikan data pengendalian penduduk berdasarkan hasil pendataan keluarga untuk di gunakan oleh OPD terkait di Kabupaten Bandung Barat.

Selain itu dari hasil pendataan keluarga dapat terlihat potensi-potensi wilayah yang ada di Kabupaten Bandung Barat seperti Pertumbuhan ekonomi, kebutuhan lapangan kerja, dan pengentasan kemiskinan yang perlu ditanggulangi bersama pemerintah dan masyarakat khususnya daerah pedesaan, memerlukan dukungan teknologi informasi dan komunikasi, dalam berbagai macam kegiatan pemerintah dan masyarakat untuk mengentaskan hal-hal tersebut memerlukan teknologi informasi dan komunikasi [4].

Berdasarkan uraian diatas penulis terdorong untuk membuat suatu sistem yang dapat digunakan tidak hanya untuk oprasional program pengendalian penduduk dan keluarga berencana saja, tetapi untuk program pembangunan lainnya. Oleh karena itu penelitian ini dilakuakan sebagai sistem untuk menampilkan data pengendalian penduduk berdasarkan hasil pendataan keluarga yang akan memudahkan penetapan sasaran bantuan- bantuan dan optimalisasi oprasional program dinas terkait serta program pembangunan lainnya yang akan dilakukan oleh seluruh OPD di Kabupaten Bandung Barat.

\section{METHOD}

Kegiatan pengumpulan data primer tentang data Kependudukan, data Keluarga Berencana, data Pembangunan keluarga dan data Anggota Keluarga yang dilakukan oleh masyarakat bersama pemerintah (BKKBN) melalui kunjungan ke keluarga dari rumah ke rumah data yang dihasilkan yaitu hasil pendataan keluarga [5].

Hasil pendataan keluarga tersebut menghasilkan data demografi yang mencakup tentang data kependudukan [6]. Data pengendalian penduduk yang berdasarkan dari hasil pendataan keluarga tersebut akan dituangkan pada sebuah peta tematik. Dalam pemetaan tematik, data divisualisasikan berdasarkan kategori tertentu dengan konsep spasial. Konsep spasial berasal dari beberapa data spasial. Data spasial terdiri dari data raster dan data vector [7].

Untuk menyempurnakan sebuah peta tematik agar dapat diintegrasikan datanya maka dibutuhkan sebuah sistem informasi untuk menunjang optimasilsasi peta data pengendalian penduduk di Kabupaten Bandung Barat dengan Sistem informasi geografis yang merupakan suatu sistem informasi berbasiskan komputer untuk menyimpan, mengelola dan menganalisis, serta memanggil data bereferensi geografis [8].

Sistem Informasi Geografis mempunyai keandalan dalam menampilkan data spasial. SIG juga dapat di manfaatkan sebagai tool interaktif dalam meningkatkan pemahaman tentang definisi lokasi, spasial (ruang), dan sebagainya [9].

Salah satu perangkat lunak penunjang sistem informasi geografis ini adalah Quantum GIS yang merupakan salah satu perangkat lunak open source di bawah proyek resmi dari Open Source Geospatial Foundation (OSGeo) yang dapat dijalankan dalam sistem operasi Windows, Mac OSX, Linux dan Unix [10].

Dari beberapa uraian permasalahan diatas menjadi sebuah motivasi untuk penulis dalam upaya mengoptimalisasi data pengendalian penduduk agar dapat terintegrasi dengan baik ke setiap OPD di Kabupaten Bandung Barat. Integrasi data merupakan salah satu faktor penting dalam menentukan kualitas sistem [11] Integrasi sistem informasi atau teknologi informasi yang tepat dapat mendukung rencana dan pengembangan dalam penerapan integrasi data dalam sistem, integrasi sistem teknologi informasi akan bermanfaat jika penerapannya sesuai dengan tujuan [12].

Optimalisasi merupakan proses dalam mengerjakan program yang telah direncanakan dengan terencana guna mencapai tujuan/target sehingga dapat meningkatkan kinerja secara optimal dan lebih efisien sehingga setiap OPD terkait tidak melakukan duplikasi pekerjaan..

\section{Stage Of Making The System}

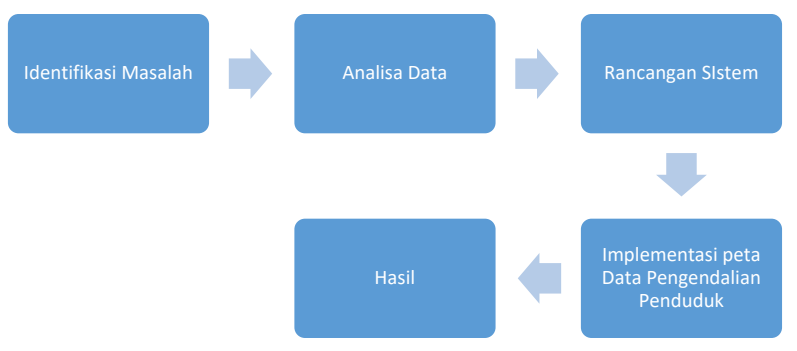

Gambar 1. Tahapan Pengembangan Penelitian

\section{Data Collection Method}

Metode yang digunakan dalam pengumpulan data dalam penelitian[13]ini diantaranya

a. Studi Literatur

Melakukan pengumpulan data yang berasal dari sumber-sumber dan literatur yang berhubungan dengan 
pengolahan aplikasi sistem informasi geografis berbasis web. Studi literatur bertujuan untuk melengkapi data dan informasi agar dapat lebih memberikan informasi yang dibutuhkan.

b. Observasi

Observasi dilakukan dengan mengunjungi kantor Dinas Pengendalian Penduduk Keluarga Berencana Pemberdayaan Perempuan dan Perlindungan Anak (DP2KBP3A) yang berlokasi di jl. Cisarua - padalarang km 2 komplek pemda Kabupaten Bandung Barat untuk mendapatkan data yang akurat terhadap objek yang akan diteliti.

\section{System Requirements Analysis}

Analisis kebutuhan sistem untuk pembangunan Sistem Informasi Geografis peta data pengendalian penduduk terdiri dari Kebutuhan fungsional sebagai berikut:

a. Sistem dapat menampilkan peta data pengendalian penduduk yang dibutuhkan oleh setiap OPD di Kabupaten Bandung Barat.

b. Sistem dapat menampilkan data cakupan hasil laporan pendataan keluarga tahun 2018, Data Rekapitulasi hasil pendataan tahun 2018 .

\section{System Design}

Tahap ini akan menerjemahkan syarat kebutuhan ke sebuah perancangan atau pemodelan (software design) yang dapat diperkirakan sebelum dilakukan coding. Perancangan pada sistem ini terdiri menjadi dua bagian yaitu rancangan proses dan rancangan antarmuka. Rancangan proses pada pembangunan sistem ini menggunakan model UML. Model yang dimaksud adalah Unified Modelling Language (UML), yang mana UML bukanlah suatu proses melainkan bahasa pemodelan secara grafis untuk menspesifikasikan, memvisualisasi kan, membangun, dan mendokumentasikan seluruh rancangan sistem perangkat lunak [14] dan perancangan antarmuka dari sistem informasi geografis yang akan dibangun.

Perancangan Sistem dijelaskan menggunakan use case diagram, activity diagram, dan sequence diagram. Interaksi aktor dengan sistem yang terjadi dalam sistem ini digambarkan dalam bentuk use case diagram. Activity diagram menggambarkan alur proses yang terjadi dalam sistem. Sequence diagram menjelaskan interaksi antar objek yang digunakan dalam sistem.

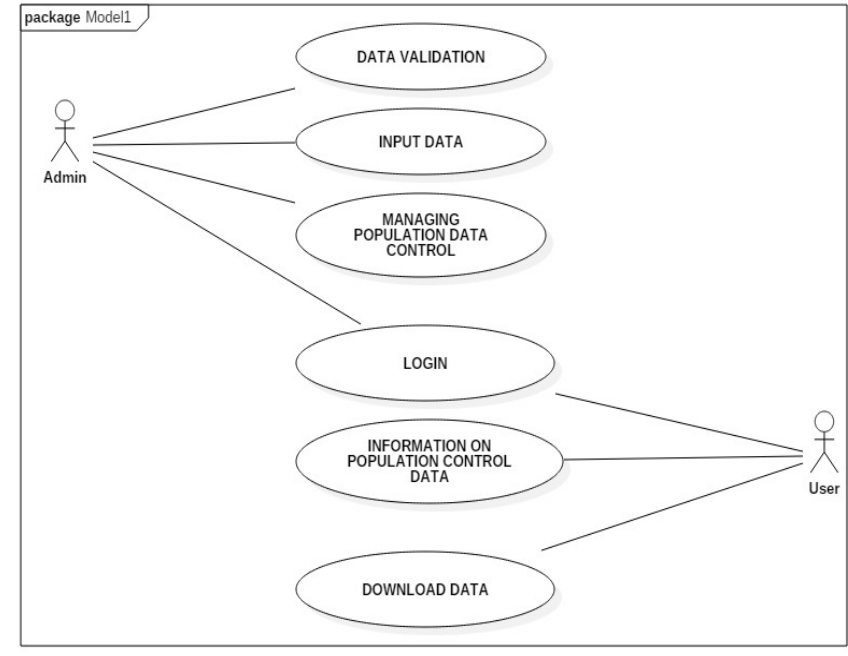

Gambar 2. Use Case diagram

Pada usecase diagram ini di definisikan untuk Admin saja yang dapat melakukan validasi data dan menginput data kedalam sistem GIS sehingga User hanya dapat mengambil data yang dibutuhkan dan tidak dapat mengedit data yang ada.

Activity Diagram Menggambarkan rangkaian aliran dari aktivitas, digunakan untuk mendeskripsikan aktivitas yang dibentuk dalam suatu operasi sehingga dapat juga digunakan untuk aktifitas lainnya [15].

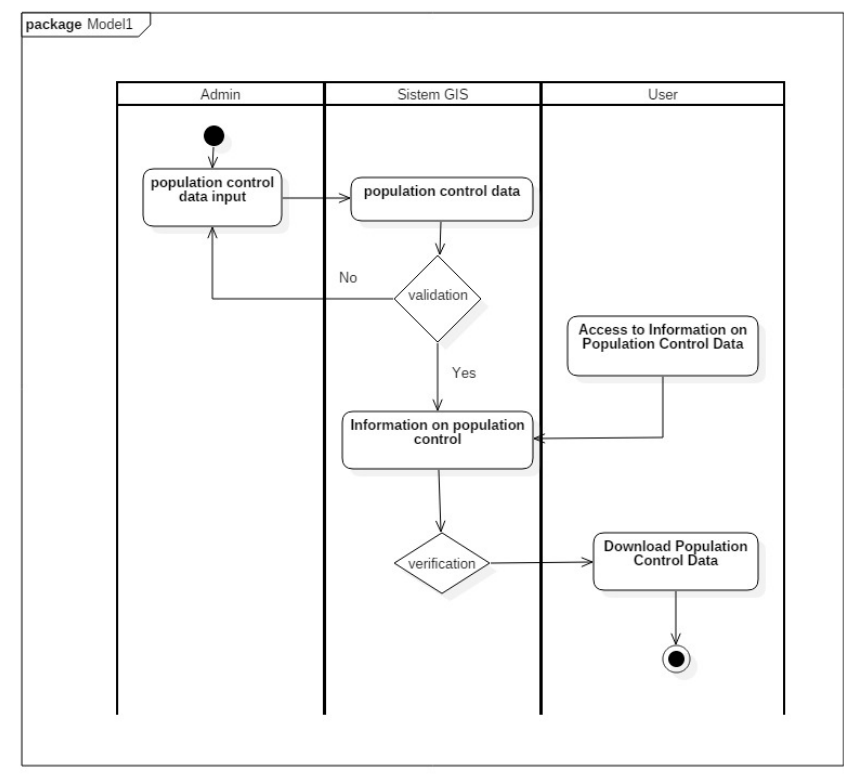

Gambar 3. Activity diagram

Perancangan sistem yang terjadi di dalam GIS adalah Admin yang berperan dalam input data dan memvalidasi data kedalam sistem GIS User hanya dapat melihat dan mengambil data saja. 


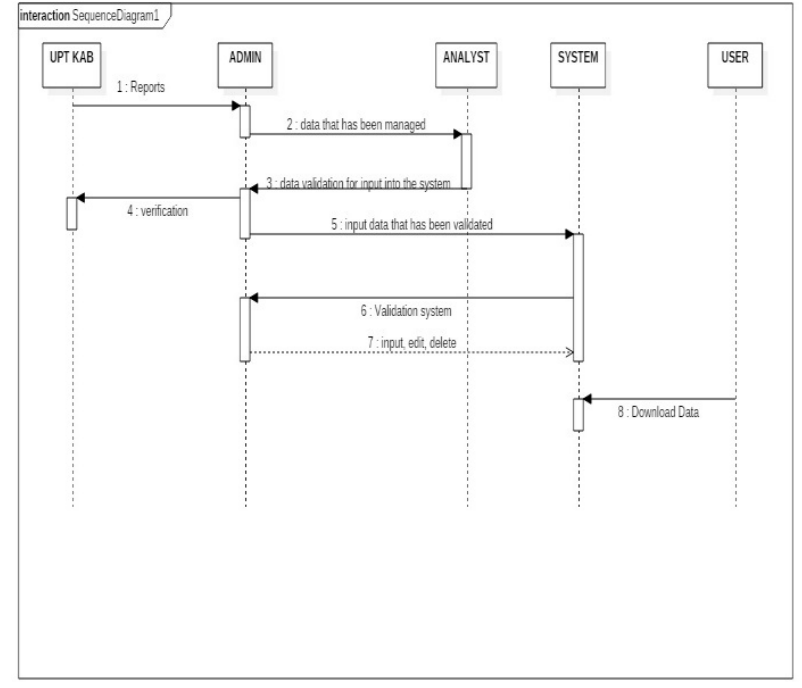

Gambar 4. Sequence diagram

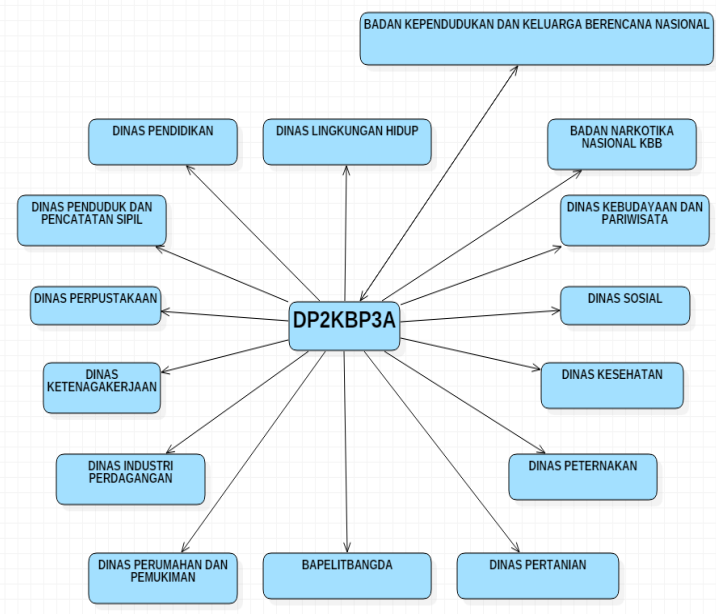

Gambar 5. Integrasi data pengendalian penduduk

Diagram tersebut menggambarkan keterkaitan data pengendalian penduduk dari DP2KBP3A ke beberapa OPD terkait. Sehingga data pengendalian penduduk yang berdasarkan hasil pendataan keluarga ini akan terintegrasi ke beberapa OPD di Kabupaten Bandung Barat.

OPD-OPD yang membutuhkan data pengendalian penduduk antara lain Dinas Kesehatan Dinas Sosial, Dinas Ketenagakerjaan, Dinas Penduduk dan Pencatatan Sipil, Dinas Perpustakaan, Dinas Perumahan dan Pemukiman, Dinas Industri Perdagangan, Dinas Pendidikam, Dinas Lingkungan Hidup. OPD-OPD tersebut membutuhkan beberapa data seperti data kesertaan JKN, Data Peserta Ber$\mathrm{KB}$ dan tidak Ber-KB, kemudian ada data tingkatan Keluarga yang dibutuhkan oleh Dinas Sosial, Dinas Ketenagakerjaan, Dinas Kesehatan, dan Dinas Penduduk dan Pencatatan Sipil.

\section{RESULTS AND DISCUSSION}

\section{System Implementation}

Sebaran Peta Data Penduduk tidak Ber-KB (Keluarga Berencana) di Kabupaten Bandung Barat

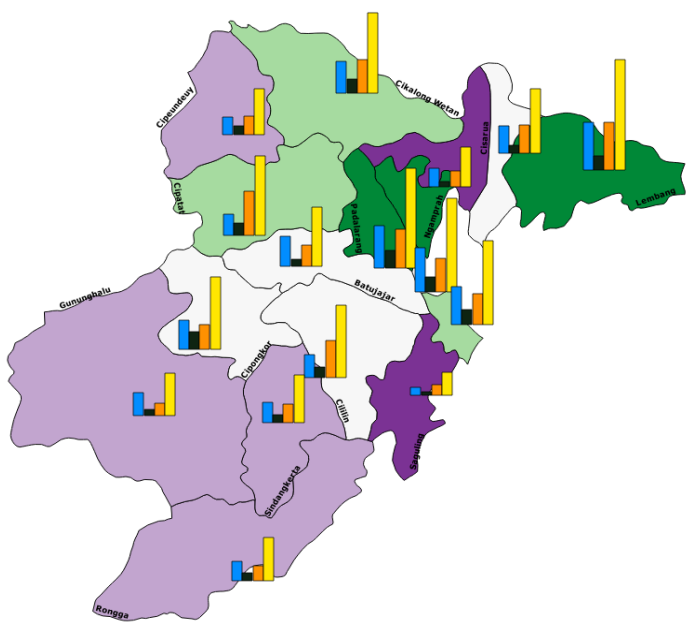

Gambar 6. Sebaran Peta Data Penduduk Tidak Ber-KB (Keluarga Berencana) di Kabupaten Bandung Barat.

Pada gambar diatas merupakan salah satu peta dari Optimalisasi peta data pengendalian penduduk di Kabupaten Bandung Barat. Peta tersebut menampilkan klasifikasi sebaran data pendudukan di Kabupaten Bandung Barat yang tidak Ber-KB (Keluarga Berencana), terlihat peta diatas terbagi dalam warna putih, hijau muda, hijau tua, ungu muda, ungu tua dan grafik.

Klasifikasi warna menunjukan besaran total dari penduduk Kabupaten Bandung Barat yang Bukan Peserta KB (Keluarga Berencana), warna ungu tua menampilkan kecamatan yang jumlah penduduk tidak Ber-Kbnya dengan rentang angka 1000 - 3200 penduduk. Warna ungu muda menampilkan kecamatan Gununghalu, Rongga, Cipeundeuy, Sindangkerta dengan rentang angka 3.300 3.851 penduduk. Kemudian warna putih adalah kecamatan Batujajar, Prongpong, Cililin, dan cipongkor yang jumlahnya ada di range angka 4.000 - 5.797 penduduk. Untuk peta yang berwarna hijau muda menampilkan kecamatan Cipatat, Cikalongwetan, Cihampelas dengan rentang angka $6.384-6.749$ penduduk, dan yang terakhir adalah peta yang berwarna hijau tua menunjukan kecamatan Ngamprah, Padalarang Lembang dengan rentang angka $7.499-8.843$ penduduk.

Pada peta tersebut ada grafik yang menunjukkan perbandingan jumlah angka penduduk yang tidak Ber-KB (Keluarga Berencana) antara kecamatan-kecamatan yang ada di Kabupaten Bandung Barat. 
Warna biru adalah ingin anak segera, warna hitam adalah ingin anak ditunda, warna jingga adalah tidak ingin anak lagi, dan yang terakhir warna kuning adalah jumlah dari bukan peserta KB (Keluarga Berencana).

Dalam grafik terlihat bahwa jumlah penduduk [16] yang tidak Ber-KB (Keluarga Berencana) ada di kecamatan Lembang dengan jumlah ingin anak segera 3.830 penduduk, ingin anak ditunda 1.198 penduduk, dan tidak ingin anak lagi 3.815 penduduk total ada 8.843 penduduk yang bukan peserta KB (Keluarga Berencana). Mengapa Lembang menjadi yang tertinggi karena dari jumlah penduduk keseluruhan di Kecamatan Lembang adalah 184.548 penduduk.

Apabila dibandingkan dengan Kecamatan Saguling yang paling rendah dengan jumlah penduduk bukan Peserta KB adalah 1.901 penduduk dari jumlah keseluruhan penduduk di Kecamatan Saguling adalah 33.104 penduduk.

Tabel 1. Data Penduduk Tidak Ber-KB (Keluarga

Berencana) di Kabupaten Bandung Barat.

\begin{tabular}{|c|c|c|c|c|c|}
\hline \multirow[b]{3}{*}{ NO } & \multirow[b]{3}{*}{ KECAMATAN } & \multicolumn{4}{|c|}{ PASANGAN USIA SUBUR } \\
\hline & & \multicolumn{4}{|c|}{ BUKAN PESERTA KB } \\
\hline & & INGIN ANAK SEGERA & INGIN ANAK DITUNDA & TIDAK INGIN ANAK LAGI & $\begin{array}{c}\text { TOTAL BUKAN } \\
\text { PESERTA KB }\end{array}$ \\
\hline 1. & Lembang & 3,830 & 1,198 & 3,815 & 8,843 \\
\hline 2. & Parongpong & 2,190 & 704 & 2,264 & 5,158 \\
\hline 3. & Cisarua & 1,505 & 454 & 1,282 & 3.241 \\
\hline 4. & Cikalongwetan & 2,584 & 1,146 & 2,721 & 6.451 \\
\hline 5. & Cipeundeuy & 1,428 & 755 & 1,538 & 3,721 \\
\hline 6. & Ngamprah & 3,555 & 1,201 & 2,743 & 7,499 \\
\hline 7. & Cipatat & 1,748 & 1,051 & 3,585 & 6,384 \\
\hline 8. & Padalarang & 3,429 & 1,424 & 3,132 & 7,985 \\
\hline 9. & Batujajar & 2,453 & 613 & 1,722 & 4,788 \\
\hline 10. & Cihampelas & 3,042 & 1,209 & 2,498 & 6,749 \\
\hline 11. & Cililin & 1,885 & 881 & 3,030 & 5,796 \\
\hline 12. & Cipongkor & 2,356 & 1,456 & 1,985 & 5,797 \\
\hline 13. & Rongga & 1,578 & 666 & 1,226 & 3,470 \\
\hline 14. & Sindangkerta & 1,653 & 693 & 1,505 & 3,851 \\
\hline 15. & Gununghalu & 1,837 & 563 & 999 & 3,399 \\
\hline 16. & Saguling & 682 & 310 & 909 & 1,901 \\
\hline & JUMLAH & 35,755 & 14,324 & 34,954 & 85,033 \\
\hline
\end{tabular}

Pada Tabel 1 diatas terlihat data penduduk bukan peserta KB. Data ini dapat digunakan oleh OPD terkait untuk dapat mensosialisasikan tentang pentingnya Ber-KB karena selain untuk menurunkan angka kelahiran juga untuk mencegah kepadatan penduduk yang tidak terkontrol.

Tabel data Penduduk Tidak Ber-KB (Keluarga Berencana) di Kabupaten Bandung Barat ini sudah dianalisa sesuai dengan jumlah penduduk di setiap kecamatan, jumlah pasangan usia subur dan jumlah peserta Ber-KB (Keluarga Berencana) yang menghasilkan data tersebut. Kemudian yang dimaksud dengan tidak Ber-KB (Kelluarga Berencana) adalah penduduk di Kabupaten Bandung Barat yang tidak memakai alat pencegah kehamilan/alat kontrasepsi apapun.

Data Penduduk Tidak Ber-KB (Keluarga Berencana) di Kabupaten Bandung Barat ini selain digunakan untuk
DP2KBP3A tentu dapat digunakan oleh beberapa OPD seperti Dinas Kesehatan..

\section{Sebaran Peta Data Penduduk Kesertaan JKN Penduduk Kabupaten Bandung Barat}

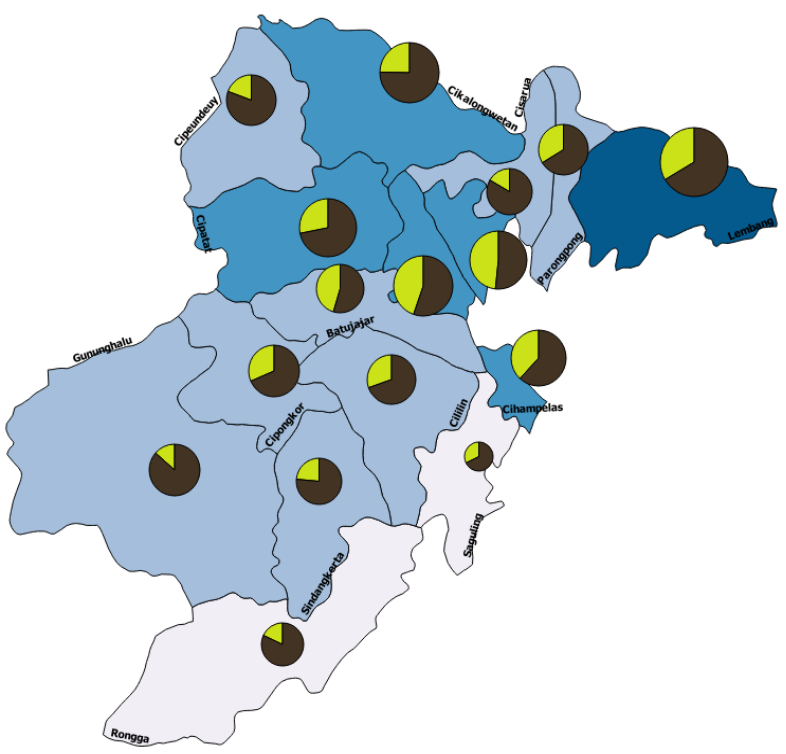

Gambar 7. Sebaran Peta Data Penduduk Kesertaan JKN Penduduk Kabupaten Bandung Barat.

Pada Gambar 4 diatas merupakan analisa peta data penduduk kesertaan JKN di Kabupaten Bandung Barat. Peta tersebut menampilkan data kesertaan JKN penduduk Kabupaten Bandung Barat dimana ternyata tidak semua penduduk Kabupaten Bandung Barat memiliki JKN yang tentunya ini sangat berguna bagi penduduk Kabupaten Bandung Barat.

Terlihat pada peta tersebut dalam klasifikasi warna abu, biru muda, biru tua, dan navy. Untuk wilayah yang berwarna abu adalah Kecamatan Rongga dan Saguling dengan rentang 22.397 - 47.425 penduduk yang belum memiliki JKN. Kemudian untuk wilayah yang berwarna biru muda adalah kecamatan Sindangkerta, Cisarua, Batujajar, Cililin, Cipeundeuy, Parongpong,m Cipongkor, Gununghalu dengan rentang angka 55.487 - 70.274 penduduk yang belum memiliki JKN. Untuk wilayah yang berwarna biru tua adalah kecamatan Cihampelas, Cipatat, Ngamprah, Cikalongwetan dengan rentang angka 80.071 - 95.000 penduduk yang belum memiliki JKN. Dan yang terakhir wilayah yang berwarna navy adalah kecamatan Lembang sendiri dengan jumlah 122.661 penduduk yang belum memiliki JKN.

Didalam peta tersebut terlihat pula diagram lingkaran yang menunjukan data kesertaan JKN yang sudah memiliki berwarna hijau sedangkan yang belum memliki berwarna hitam. 
Pada dasarnya peta yang ditampilkan dalam Sistem Informasi Geografis ini adalah untuk mengoptimalkan dan mengefisiensikan pekerjaan daripada DP2KBP3A dan beberapa OPD terkait di Bandung Barat. Peta Data Penduduk Kesertaan JKN Penduduk Kabupaten Bandung Barat ini dibutuhkan oleh beberapa OPD seperti Dinas Sosial, Dinas Kesehatan, Dinas Penduduk dan Pencatatan Sipil..

Tabel 2. Data Penduduk Kesertaan JKN Penduduk Kabupaten Bandung Barat.

\begin{tabular}{|c|c|c|c|c|c|c|c|}
\hline \multirow{3}{*}{ NO } & \multirow{3}{*}{ KECAMATAN } & \multicolumn{4}{|c|}{ MEMLLIKI JKN } & \multirow{3}{*}{$\begin{array}{l}\text { TIDAK } \\
\text { JUMLAH }\end{array}$} & \multirow{3}{*}{ TOTAL } \\
\hline & & \multirow{2}{*}{$\begin{array}{c}\text { BPJS - PBI } \\
\text { JUMLAH }\end{array}$} & \multirow{2}{*}{$\begin{array}{c}\text { BPJS - NON PBI } \\
\text { JUMLAH }\end{array}$} & \multirow{2}{*}{$\begin{array}{c}\text { NON BPJS } \\
\text { JUMLAH } \\
\end{array}$} & \multirow{2}{*}{$\begin{array}{l}\text { TOTAL } \\
\text { JUMLAH }\end{array}$} & & \\
\hline & & & & & & & \\
\hline (1) & (2) & (3) & (5) & $(7)$ & (9) & (11) & (13) \\
\hline 1. & Saguling & 8,987 & 1,525 & 195 & 10,707 & 22,397 & 33,104 \\
\hline 2. & Rongga & 8,116 & 1,728 & 620 & 10,464 & 47,425 & 57,889 \\
\hline 3. & Sindangkerta & 12,202 & 3,008 & 1,936 & 17,146 & 55,487 & 72,633 \\
\hline 4. & Cisarua & 5,561 & 3,239 & 2,434 & 11,234 & 56,269 & 67,503 \\
\hline 5. & Batujajar & 18,778 & 25,771 & 6,541 & 51,090 & 61,411 & 112,501 \\
\hline 6. & Cillilin & 19,708 & 6,843 & 1,881 & 28,432 & 65,198 & 93,630 \\
\hline 7. & Cipeundeuy & 10,495 & 3,700 & 1,660 & 15,855 & 65,925 & 81,780 \\
\hline 8. & Parongpong & 11,895 & 18,117 & 4,530 & 34,542 & 67,960 & 102,502 \\
\hline 9. & Cipongkor & 24,108 & 5,461 & 2,217 & 31,786 & 69,126 & 100,912 \\
\hline 10. & Gununghalu & 6,548 & 3,058 & 1,190 & 10,796 & 70,274 & 81,070 \\
\hline 11. & Cihampelas & 31,977 & 12,191 & 5,177 & 49,345 & 80,071 & 129,416 \\
\hline 12. & Cipatat & 21,922 & 8,981 & 3,291 & 34,194 & 87,406 & 121,600 \\
\hline 13. & Ngamprah & 24,517 & 49,187 & 8,410 & 82,114 & 87,654 & 169,768 \\
\hline 14. & Cikalongwetan & 19,026 & 8,440 & 3,152 & 30,618 & 93,180 & 123,798 \\
\hline 15. & Padalarang & 26,748 & 44,160 & 5,970 & 76,878 & 95,000 & 171,878 \\
\hline 16. & Lembang & 32,190 & 23,283 & 6,414 & 61,887 & 122,661 & 184,548 \\
\hline & KABUPATEN & 282,778 & 218,692 & 55,618 & 557,088 & $1,147,440$ & $1,704,528$ \\
\hline
\end{tabular}

Pada Tabel 2 diatas terlihat data penduduk Kabupaten Bandung Barat yang sudah dan belum memiliki JKN. Data ini sudah dianalisa sesuai dengan jumlah penduduk disetiap kecamatan, berdasarkan Tahapan Keluarga, Jumlah Kepala Keluarga, data Penduduk yang Bekerja dan Tidak Bekerja sehingga menghasilkan data tersebut.

\section{CONCLUSIONS}

- Berdasarkan penelitian ini dapat disimpulkan bahwa Dinas Pengendalian Penduduk Keluarga Berencana Pemberdayaan Perempuan dan Perlindungan Anak Kabupaten Bandung Barat memiliki data pengendalian penduduk berdasarakan pendataan keluarga yang dikelola setiap tahunnya. Data- data mengenai pengendalian penduduk di Kabupaten Bandung Barat ini dihimpung dan diolanh dengan cara diklasifikasikan berdasarkan kategori agar mudah digunakan. Data data tersebut menjadi dasar pembuatan layer pada petapeta yang ada pada Sistem Informasi Geografis ini. Layer pada peta ditampilkan dengan berbagai gradasi warna agar lebih menarik pengguna Sistem Informasi Geografis dan agar mudah dalam Penyampaian Informasi

- Dengan adanya Sistem Informasi Geografis peta data ini akan mendapatkan hasil data spasial dan data non spasial yang akan dengan mudah digunakan oleh OPDOPD yang ada di Kabupaten Bandung Barat.

- Data pengendalian penduduk berdasarkan hasil pendataan keluarga untuk Setiap OPD sudah dapat terintegrasi dengan Dinas Pengendalian Penduduk
Keluarga Berencana dan Perlindungan Anak sesuai dengan data yang dibutuhkan sehingga memudahkan pengguna untuk tidak perlu lagi datang ke Kantor Dinas Pengendalian Penduduk Keluarga Berencana Pemberdayaan Perempuan dan Perlindungan Anak Kabupaten Bandung Barat untuk mendapatkan informasi mengenai data Pengendalian penduduk di Kabupaten Bandung Barat

- Dinas Pengendalian Penduduk Keluarga Berencana Pemberdayaan Perempuan dan Perlindungan Anak Kabupaten Bandung Barat mendapatkan kemudahan dalam mengolah data pengendalian penduduk berdasarkan pendataan keluarga, kemudahan yang didapat merupakan melihat data, menambah data, mengedit data dan menghapus data secara real time..

\section{REFERENCES}

[1] F. P. Putra, P. Studi, R. Perangkat, L. Jurusan, T. Informatika, and P. N. Bengkalis, "Peta Digital Demografi Penduduk Tingkat Desa Berbasis Web Menggunakan Google Maps API," pp. 33-41.

[2] Y. R. Nur Rizky, A. L. Nugraha, and A. P. Wijaya, "Jurnal Geodesi Undip Januari 2015 Jurnal Geodesi Undip Januari 2015," Geod. Undip, vol. 4, pp. 172 182, 2015.

[3] M. R. Istambul, "E-Learning Design Activity to Improve Student' s Knowledge and Skills : A Case Study of Database Design Courses," vol. 6, no. 6, 2016.

[4] R. A. E. Virgana, "Membangun Awareness Kesenjangan Telekomunikasi Pedesaan di Jawa Barat Dengan GIS Analysis for ICT Blank Spot Area menuju Jabar Cyber Province," Semin. Nas. Tek. Elektro 2016, vol. 2, pp. 10-17, 2016.

[5] BKKBN, "Batasan dan Pengertian MDK." [Online]. Available:

http://aplikasi.bkkbn.go.id/mdk/BatasanMDK.aspx.

[6] N. SYAADAH, "ANALISIS DAMPAK PERTAMBAHAN PENDUDUK TERHADAP PENYERAPAN ANGKATAN KERJA," GEOGRAFI, vol. 2, pp. 61-70, 2014.

[7] H. Herrmann and H. Bucksch, "Thematic Map," Dict. Geotech. Eng. Geotech., pp. 1385-1385, 2014.

[8] K. M. Wibowo, K. Indra, and J. Jumadi, "Sistem Informasi Geografis (SIG) Menentukan Lokasi Pertambangan Batu Bara di Provinsi Bengkulu Berbasis Website," J. Media Infotama, vol. 11, no. 1, pp. 51-60, 2015.

[9] D. Hamdani and R. A. . V. Targa Saptanji, "Perancangan Model Sistem Informasi Geografis Pemetaan Sebaran Demam Berdarah di Wilayah Kota Bandung," Pros. Annu. Res. Semin. 2018, vol. 
4, no. 1, pp. 978-979, 2018.

[10] S. Hussein and Werdiningsih, "Pemanfaatan Sistem Informasi Geografis (SIG) berbasis Open Source untuk Analisis Kerentanan Air Permukaan SubDAS Blongkeng," Teknol. Inf. dan Komun., vol. 2012, no. Sentika, pp. 1-6, 2012.

[11] R. S. Dewi, "Analisis Dampak Integrasi Data Terhadap Kecepatan Pelayanan Publik Di Kota Surabaya," pp. 90-97.

[12] A. Wuryanto, "Integrasi Sistem Informasi Dan Teknologi Informasi Melalui Metode Enterprise Architecture Planning pada PT. Kayu Permata Bekasi," ILMU Pengetah. DAN Teknol. Komput., vol. 3, no. 2, pp. 151-158, 2018.

[13] R. Arrasyid, D. Rohmat, Jupri, S. Himayah, A. R. Affriani, and R. Ridwana, "The Suggest of Rubber Crops Cultivation Development Zonation at West Bandung Regency," IOP Conf. Ser. Earth Environ. Sci., vol. 286, no. 1, 2019.

[14] M. R. Istambul, "PRODUK USAHA MIKRO KECIL MENENGAH ( Studi Kasus UMKM Makehate Bandung ),” pp. 259-265, 2015.

[15] D. Alan, B. Haley, and D. Wixom, Systems Analysis Design with UML Version 2.5: An Object-Oriented Approach. 2015.

[16] M. Mujib et al., "The Application of Differential Equation of Verhulst Population Model on Estimation of Bandar Lampung Population," $J$. Phys. Conf. Ser., vol. 1155, no. 1, 2019. 